\title{
Estado, editoras e ensino: o papel da política na produção, avaliação e distribuição dos livros didáticos de História no Brasil (1938-2012)
}

State, publishers and teaching: the role of politics in the production, evaluation and distribution of History textbooks in Brazil

Júlia Silveira Matos*

Adriana Kivanski de Senna**

\section{REsumo}

A ampla distribuição de livros didáticos no Brasil, tanto no ensino Fundamental quanto no Médio, é garantida por uma política governamental de educação que atualmente se efetiva pelo Programa Nacional do Livro Didático (PNLD). Entretanto, a trajetória das políticas voltadas para a avaliação, regulação e distribuição dos livros didáticos no Brasil foi marcada por três momentos específicos da história nacional. O primeiro ainda no século XIX, com a criação da Comissão de Instrução Pública; o segundo, com a Comissão Nacional do Livro Infantil (1936), a Comissão Nacional do Ensino Primário (1938) e a Comissão Nacional do Livro Didático (1938); por fim, o terceiro momento tem a criação em 1985, já no final do governo militar, do Programa Nacional do Livro Didático (PNLD). No presente texto analisaremos o papel histórico desses órgãos no processo de seleção e distribuição dos livros didáticos para as escolas públicas no Brasil.

Palavras-chave: Estado; livros didáticos; políticas de educação; avaliação.
Abstract

If we take a look to the history of the textbook in Brazil, we'll see that their distribution to Elementary and High Schools is guaranteed by a governmental national educational policy put to effect in Brazil through the Programa Nacional do Livro Didático. However, the trajectories of evaluation, regulation and distributional policies of textbooks in Brazil have been marked by three specific moments in national history: the first one, still in the 19th century, with the creation of the Comissão de Instrução Pública; the second one with the Comissão Nacional do Livro Infantil (1936), the Comissão Nacional do Ensino Primário (1938) and the Comissão Nacional do Livro Didático (1938) and the third one with the creation, in 1985 , at the end of the military regime, of the Programa Nacional do Livro Didático, shortened to PNLD. Thus, in the present paper we analyze the historical role of both of these organs in the process of selection and distribution of the textbooks to Brazilian public schools.

Keywords: State; textbooks; educational policies; evaluation.

\footnotetext{
* Universidade Federal do Rio Grande (FURG).jul_matos@hotmail.com

** Universidade Federal do Rio Grande (FURG). adrianasenna@vetorial.net
} 
A história do livro didático se inscreve em outra trajetória mais ampla que é a própria história do livro, marcada pela ação de Gutenberg e sua prensa, que permitiu uma produção dos livros em maior escala e com menor custo. O livro nesse processo deixou de ser uma propriedade de valor para a representação de um status social e paulatinamente adquiriu papel central nos processos de ensino/aprendizagem, na lógica de uma educação humanista e depois iluminista. Em meio a essa transformação do papel do livro, surgiu o que hoje chamamos de livro didático ou manual escolar, que na escola se tornou não apenas o recurso didático central do professor como seu apoio para construção do planejamento e do currículo escolar. Nesse ínterim, de acordo com Alain Choppin, "a concepção de um livro didático inscreve-se em um ambiente pedagógico específico e em um contexto regulador que, juntamente com o desenvolvimento dos sistemas nacionais ou regionais, é, na maioria das vezes característico das produções escolares..." (Choppin, 2004, p.554). As fronteiras entre as práticas pedagógicas e os contextos regulares poderiam estar distantes, entretanto, conforme analisou esse autor, quando se trata de livros didáticos não existe tal fronteira, pois, as práticas pedagógicas são reguladas por contextos específicos. Nesse caso, os livros didáticos são um instrumento fundamental das políticas educacionais, especialmente no Brasil, como analisaremos no presente texto.

Ao analisarmos a história do livro didático no Brasil, veremos que sua ampla distribuição tanto no ensino Fundamental quanto no Médio é garantida por uma política governamental de educação que atualmente se efetiva pelo Programa Nacional do Livro Didático (PNLD). Entretanto, a trajetória das políticas voltadas para a avaliação, regulação e distribuição dos livros didáticos foi marcada por três momentos específicos da história nacional. O primeiro ainda no século XIX, com a criação da Comissão de Instrução Pública, responsável por elaborar projetos de lei que, de acordo com Souza (2000, p.10), visassem "a melhor organização pedagógica para a escola primária”. Apesar do seu curto tempo de existência, cerca de 6 meses, ela se propunha a ser instrumento de promoção dos fundamentos da nacionalidade brasileira através da educação. Um segundo momento ocorreu já no século XX, marcado pela existência de três comissões, como apontou Tania Regina de Luca: a Comissão Nacional do Livro Infantil (1936), a Comissão Nacional do Ensino Primário (1938) e a Comissão Nacional do Livro Didático (1938), criadas na gestão do 
ministro Gustavo Capanema em meio à implantação do Estado Novo no Brasil. Por fim, no terceiro momento cria-se em 1985, já no final do governo militar, do Programa Nacional do Livro Didático, o chamado PNLD.

Dos três momentos apontados, o que nos interessa em nossa análise é, justamente, o processo de transição das políticas de avaliação, regulação e distribuição dos livros didáticos entre a Comissão Nacional do Livro Didático (CNLD) e o PNLD. Isso porque ambos os órgãos atuaram e atuam mediante o estabelecimento de diretrizes para a própria elaboração dos livros didáticos e influíram e ainda influem, no caso do PNLD, nas formas como é apresentado o conhecimento das disciplinas escolares. Por meio da função avaliativa e reguladora, tanto a Comissão Nacional quanto o PNLD determinaram e determinam quais manuais escolares poderão ser distribuídos e, assim, utilizados pelas instituições de ensino públicas. Nessas duas situações vemos a presença do governo e de suas políticas, não apenas das diretrizes educacionais, mas no próprio processo de ensino-aprendizagem exercido dentro das salas de aula. Por mais que, conforme afirmou Kazumi Munakata (2009), os professores ainda sejam capazes de ministrar ótimas aulas a partir de péssimos livros, o livro didático é seu principal recurso em sala e, portanto, muitas vezes um limitador de suas ações educativas e reflexivas. Nesse sentido,

O próprio PNLD lamenta que os professores adotam sistematicamente os livros mal avaliados ... simplesmente ignoram o Guia de Livros Didáticos, não por acharem difíceis as resenhas - como avaliou um documento do PNLD, e sim porque preferem fazer suas escolhas "com o livro na mão". (Munakata, 2009, p.144)

A questão que se abre a partir da afirmação de que seria 'lamentável' professores escolherem para utilização em suas salas de aula livros 'mal' avaliados é: para quem esses livros foram mal avaliados? Por mais que saibamos que o PNLD possui uma comissão de especialistas nas áreas de ensino que atuam diretamente na avaliação dos manuais escolares inscritos no edital em vigor, também é necessário considerarmos que os docentes no Brasil possuem realidades diferentes em suas salas de aula: especificidades regionais, dificuldades locais de estrutura e recursos, públicos específicos e outras tantas diversidades, as quais os avaliadores muitas vezes desconhecem e não preveem em suas tabelas avaliativas. Sendo assim, a má avaliação de alguns manuais não 
implica diretamente que eles não apresentem possibilidades de 'boa' utilização em diferentes realidades. Também podemos considerar que mesmo dentro de um espaço reflexivo de liberdade intelectual dos professores que optam por ignorar as indicações do guia, como apontou a autora, ainda assim, no universo editorial dos livros didáticos, as diretrizes instituídas pelo PNLD influem na elaboração desses livros, sejam eles os mais bem avaliados ou não. Dessa forma, no presente texto analisaremos o papel histórico desses dois órgãos no processo de seleção e distribuição dos livros didáticos para as escolas públicas no Brasil.

\section{O ensino de História e a Comissão Nacional do Livro DidÁtico (CNLD)}

Dentro do processo de criação de um órgão responsável pela regulação, avaliação e circulação de livros didáticos, podemos inferir que o ensino de História foi um alvo, pois é nele que encontramos um espaço relativamente amplo de possibilidades de crítica social e política. E mais do que simplesmente o ensino de História, os livros didáticos foram desde a década de 1930 produtos centrais dentro das políticas educacionais. Segundo Ana Maria Monteiro,

Considerando o caso brasileiro, verifica-se que o entendimento da importância estratégica do livro didático nas políticas educacionais remonta à década de 1930, durante o Estado Novo, quando foi instituída, pelo Decreto-Lei n. 1.006, de 30 de dezembro de 1938, a Comissão Nacional do Livro Didático (CNLD), estabelecendo a primeira política de legislação e controle de produção e circulação do livro didático no país. (Monteiro, 2009, p.180)

Monteiro destaca que foi a partir do Decreto-Lei n. 1.006, de dezembro de 1938, o qual determinou a criação da CNLD, que os livros didáticos se tornaram no Brasil produtos de regulação e controle do Estado, ou seja, essa foi a primeira política voltada para o controle da produção dos manuais escolares. Essa característica dá à CNLD o papel de criadora ou constituidora de uma nova cultura editorial no Brasil, regulada por diretrizes propostas pelo Estado. Ainda de acordo com a autora, a CNLD foi fruto da preocupação do Ministério da Educação e Saúde com a formação da nacionalidade brasileira, 
e para isso "buscava controlar o material a ser utilizado pelos alunos nas escolas" (ibidem, p.180).

Dessa forma, quando analisamos o papel da criação da CNLD em 1938, buscamos perceber como essa instituição atuou como limitadora e reguladora dos conteúdos veiculados nos livros didáticos, especificamente os de História e, dessa forma, contribuiu para uma profunda mudança no mercado editorial brasileiro de livros didáticos.

De acordo com Tania Regina de Luca, cabia a essa Comissão o papel de executar "a análise dos materiais didáticos submetidos pelos autores e editores, elaborar uma relação oficial para servir de orientação à escolha dos professores de escolas públicas ou privadas, além de estimular e orientar a produção de livros didáticos..." (Luca, 2009, p.167). Entre suas funções não encontramos a produção dos manuais escolares, mas, como demonstrou a autora, seu papel era centrado na regulação e autorização dos livros que poderiam ou não ser utilizados nas escolas públicas. Assim, apesar de não instituir um manual único para todas as escolas, a Comissão acabou constituindo um conjunto de diretrizes que orientavam a produção dos livros didáticos. Isso porque se um autor e editora queriam ter seu produto autorizado, precisavam seguir as orientações e diretrizes propostas pela Comissão. Afinal, segundo Luca, a Comissão "limitava o universo de opções, na medida em que a seleção deveria ser feita a partir da lista oficial, sob a responsabilidade de especialistas nomeados para a tarefa pelo presidente da República" (Luca, 2009, p.167). Essa lista oficial continha as indicações dos livros aprovados para utilização nas escolas públicas e que, consequentemente, não apresentassem qualquer crítica ao regime político vigente no país. Ainda de acordo com a autora, a CNLD tinha a preocupação de "centralizar as decisões, conduzir uma política unificada para todo o país e intervir na produção, com a delimitação de diretrizes gerais que puniam qualquer crítica ao regime político em vigor e ao chefe da nação...” (Luca, 2009, p.167). Esse último aspecto evidenciado pela autora revela a face da censura aos conteúdos apresentados nos manuais escolares avaliados, exercida pela Comissão. Entretanto, não apenas revela o processo de censura dos manuais didáticos, como também os instrumentos utilizados ainda no governo Vargas que paulatinamente serviram para uniformizar a produção dos livros didáticos e ainda mais, ofertaram as diretrizes para a constituição de um padrão para a apresentação dos manuais escolares. Esse padrão, constituído dentro de um 
processo histórico relativamente longo, se materializou na própria divisão dos conteúdos de história, foco do presente estudo, de forma quadripartite, a qual não tem sido discutida no âmbito da produção dos livros didáticos nos debates do ensino de História de forma enfática ou problematizadora.

Nessa perspectiva, é preciso lembrar que a criação dessa Comissão foi acompanhada de reformas de ensino como as implementadas por Francisco Campos e Gustavo Capanema entre os anos de 1931 e 1942. Nessas, vemos o modelo quadripartite do ensino de História 'francês' reafirmado no Brasil. Como afirmou Selva Guimarães Fonseca, a História era dividida entre conhecimentos de História Universal e do Brasil, “dividida em duas séries, o primeiro conjunto compreendendo a História do Brasil até a Independência, e o segundo compreendendo a História do Brasil do $1^{\circ}$ Reinado até aquele momento, o Estado Novo" (Fonseca, 2010, p.49). A adoção desse modelo de ensino de História pela política educacional, defendida dentro dos ministérios de Campos e Capanema, demonstra a intenção de regulação dos conteúdos ensinados nas escolas nacionais, não apenas para organização, mas com uma função política definida. Segundo Jean Chesneaux (1976), a organização e divisão dos conteúdos de História na perspectiva quadripartite no final do século XIX e primeira metade do XX apresenta uma função político-ideológica bem fundamentada. Em direção ao que esse autor afirma, Fonseca explica que nos conteúdos de História se evidencia:

No caso da Idade Antiga, destaca-se a antiguidade greco-romana e seus valores culturais como base da cultura burguesa europeia. No período medieval, salienta-se a Idade Média cristã, exaltando os valores da civilização cristã. O período moderno ... representa a pretensão da burguesia de completar a história, controlando, em nome da modernidade, o futuro da humanidade. A Idade Contemporânea apresenta o domínio do Ocidente sobre o mundo, através da elaboração de um quadro coerente e global do mundo. Nos séculos XIX e XX, os países industrializados, "civilizados", tornam-se os "guias naturais da história africana, asiática ou americana". (Fonseca, 2010, p.50)

Em uma perspectiva europeia, ainda centrada na ideologia civilizatória defendida no processo de neocolonialismo do século XIX, o ensino de História colocava os colonizadores europeus em um papel de destaque no processo de desenvolvimento do Brasil enquanto parte do continente americano e, 
principalmente, em industrialização nas primeiras décadas do século XX. Em um contexto pós-Primeira Guerra Mundial esse tipo de ensino de história justificava e legitimava o papel dos países vencedores enquanto civilizadores. Esse modelo de ensino da história influenciou toda a produção não apenas nas salas de aula, mas também nas pesquisas. De acordo com Fonseca, a partir de 1939 as teses defendidas na Universidade de São Paulo (USP) apresentaram em suas análises uma centralidade nas pesquisas voltadas para questões e estruturas da História quadripartite, o que contribuiu para que essa divisão dos conteúdos históricos se enraizasse de tal forma no ensino de História que até hoje é considerada modelo básico do ensino Fundamental, Médio e Superior. Portanto, vemos que as políticas educacionais, os livros didáticos e as perspectivas do ensino de História estão intimamente ligados. Para compreendermos melhor as nossas atuais formas de ensino dos conhecimentos históricos precisamos antes analisar como se estruturaram essas diretrizes reguladoras da produção e distribuição dos livros didáticos.

A CNLD foi criada pelo Decreto-lei n. 1.006, de 30 de dezembro de 1938, e entre seus 40 artigos estipulava "que, a partir de 1 de janeiro de 1940, livros sem autorização do ministério não poderiam ser utilizados nas escolas pré-primárias, primárias, normais, profissionais e secundárias de toda a República" (Luca, 2009, p.167). Essa determinação do Decreto deu início a um processo de normatização da produção dos livros didáticos no Brasil.

Para a composição da Comissão Nacional foram escolhidos intelectuais, professores, padres e militares: "a CNLD foi composta por um grupo de intelectuais, escolhidos por Gustavo Capanema, não de forma aleatória, mas organizada de acordo com as possibilidades do Ministério" (Ferreira, 2008, p.16). Essa escolha contou com uma diretriz veiculada no Decreto-lei 1.006/38, no qual constava que

A Comissão deveria ser integrada por sete membros, designados pelo Presidente da República, escolhidos dentre "pessoas de notório preparo pedagógico e reconhecimento moral” (Decreto-Lei n. 1.006/38), divididos em especializações: duas especializadas em metodologia das línguas, três em metodologia das ciências e duas em metodologia das técnicas. Os membros da comissão não poderiam ter nenhuma ligação de caráter comercial com qualquer casa editorial. (Filgueiras, 2008, p.2) 
Apesar de o Decreto não permitir qualquer ligação entre seus membros e a publicação de obras, havia certo relaxamento da lei, pois em algumas situações os livros de autoria total ou parcial de algum componente da comissão poderiam ser submetidos ao ministro e ao presidente da República e, se autorizados, posteriormente apresentados à Comissão. Claro que aqui podemos considerar que os nomes escolhidos para compor o grupo de avaliadores deveriam apresentar alinhamento com o governo e suas políticas educacionais. Sendo assim, estabelecia-se uma aproximação e ao mesmo tempo um alinhamento entre avaliadores, editores e autores de livros didáticos. Conforme afirmou Tania Regina de Luca, "as relações com o Catete eram cuidadosamente nutridas, como ilustra o hábito de remeter livros para Getúlio Vargas e sua filha, Alzira, devidamente acompanhados de 'bilhetes gentis"' (Luca, 2009, p.170). Esse hábito, instituído a partir da implementação dos processos de avaliação e regulação dos manuais escolares através da CNLD, demonstra como se estabeleceu um sistema dialético entre as diretrizes do governo e a produção de novos livros didáticos.

Afinal, ao instituir uma lista de livros autorizados e ainda divulgar os motivos das reprovações dos títulos não autorizados, "detalhava o processo de autorização e os motivos que justificavam o seu veto" (Luca, 2009, p.167), fornecia as bases normatizadoras da produção dos manuais escolares. Essa medida aproximou os editores e autores das políticas educacionais do governo, cerceando de forma direta a produção e criação dos livros didáticos. Isso porque

a criação da comissão não foi um ato isolado, antes se articulava a um conjunto de mudanças no campo educacional, iniciadas já em 1931 com a chamada Reforma Francisco Campos, que estabeleceu novas bases para o sistema de ensino do país como um todo, e que teve continuidade com a Lei Orgânica do Ensino Secundário, de 1942. (Luca, 2009, p.167-168)

Como bem apontou a autora, as normas instituídas pela CNLD estavam articuladas diretamente com a visão política do Estado Novo para a educação, e portanto ela se articulou com as diretrizes implementadas na sequência. $\mathrm{Na}$ Lei Orgânica do Ensino Secundário 4.244, de 1942, citada, encontramos nos incisos do artigo 24 as diretrizes para o ensino de História e Geografia e a de- 
terminação de que sejam ensinados conteúdos próprios de moral e cívica, conforme segue:

$\$ 1^{\circ}$ Para a formação da consciência patriótica, serão com frequência utilizados os estudos históricos e geográficos, devendo, no ensino de história geral e de geografia geral, ser postas em evidência as correlações de uma e outra, respectivamente, com a história do Brasil e a geografia do Brasil.

$\$ 2^{\circ}$ Incluir-se-á nos programas de história do Brasil e de geografia do Brasil dos cursos clássico e científico o estudo dos problemas vitais do país.

$\$ 3^{\circ}$ Formar-se-á a consciência patriótica de modo especial pela fiel execução do serviço cívico próprio do Juventude Brasileira, na conformidade de suas prescrições.

$\$ 4^{\circ}$ A prática do canto orfeônico de sentido patriótico é obrigatória nos estabelecimentos de ensino secundário para todos os alunos de primeiro e de segundo ciclo.

No ensino de História e Geografia seriam trabalhados os conteúdos de forma a propor: o desenvolvimento de uma 'consciência patriótica', a percepção dos problemas brasileiros e, como registrado no inciso $3^{\circ}$, a formação da juventude para o serviço cívico. Esse tipo de ensino de História e Geografia apresentava um forte viés ideológico dirigido por uma propaganda voltada para o apoio e a legitimação do Estado Novo. Como vemos na citação, o foco de ensino recairia no desenvolvimento de uma educação patriótica, ou seja, os manuais que não seguissem essa orientação seriam descartados ou vetados da listagem oficial de livros autorizados para utilização no ensino público. Nessa mesma direção, afirmou Bomeny que o objetivo das reformas educacionais implementadas pelo Ministério da Educação e Saúde dentro do Estado Novo era instituir uma política para a educação capaz de:

Formar um "homem novo" para um Estado Novo, conformar mentalidades e criar o sentimento de brasilidade, fortalecer a identidade do trabalhador, ou por outra forjar uma identidade positiva no trabalhador brasileiro; tudo isso fazia parte de um grande empreendimento cultural e político para o sucesso do qual contava-se estrategicamente com a educação por sua capacidade universalmente reconhecida de socializar os indivíduos nos valores que as sociedades, através de seus segmentos organizados, querem ver internalizados. (Bomeny, 1999, p.139) 
Na perspectiva apresentada pela autora, a política educacional implementada pelo Estado Novo e a chamada Reforma Capanema tinham por foco legitimar a visão do Estado mediante um ensino que fosse capaz de forjar uma nova identidade nacional, focada na imagem do trabalhador patriótico. Dessa forma, por meio da educação os ideais do novo regime instituído pelo Estado Novo seriam propagados, como afirmou Rita de Cássia Ferreira:

A política cultural elaborada pelo Estado Novo e coordenada, principalmente, pelo Ministério de Educação e Saúde, obteve, sob a direção de Gustavo Capanema (1934- 1945), um amplo espaço para propagação dos ideais do regime, tendo na educação uma das principais estratégias de viabilização da construção do Estado Nacional. (Ferreira, 2008, p.22)

O objetivo da política cultural do Ministério da Educação e Saúde era, portanto, forjar as bases ideológicas para a construção de uma nova nação. Nesse sentido, era preciso implementar uma política capaz de, segundo Ferreira, uniformizar, dentro dos limites possíveis, o ensino brasileiro, com vistas a "padronizar comportamentos, atividades e interesses da juventude brasileira. $\mathrm{O}$ conhecimento do idioma, noções básicas de Geografia e História da Pátria, arte popular e folclore, formação cívica, moral e a consciência do bem coletivo sobreposto ao individual seriam a base da formação do cidadão político" (Ferreira, 2008, p.22). Entretanto, a padronização de comportamentos dos jovens através do ensino exigia mais do que uma proposta de política cultural e, sim, uma nova estrutura administrativa do próprio Ministério de Educação e Saúde, o qual foi modificado de forma a centralizar os processos de avaliação e controle dos livros didáticos, conforme demonstrado na Figura 1.

Como vemos no gráfico criado por Ferreira, o Livro Didático estava dentro das Comissões Nacionais ao lado do Ensino Primário, enquanto departamento em separado no Ministério. Essa estrutura revela que, mesmo considerando o quanto eram pouco ágeis as análises e intervenções da CNLD, como bem apontou Tania Regina de Luca, a avaliação e regulação da utilização dos livros didáticos nas escolas era um assunto de fundamental preocupação do Ministério. Com base na Lei Orgânica do Ensino Secundário de 1942, que ficou em vigência até a instituição da Lei de Diretrizes e Bases (LDB) em 1961, e na própria CNLD, o governo conseguiu interferir diretamente na educação e nas formas de ensino, principalmente no ensino de História. Essa interferência se 


\section{Figura 1}
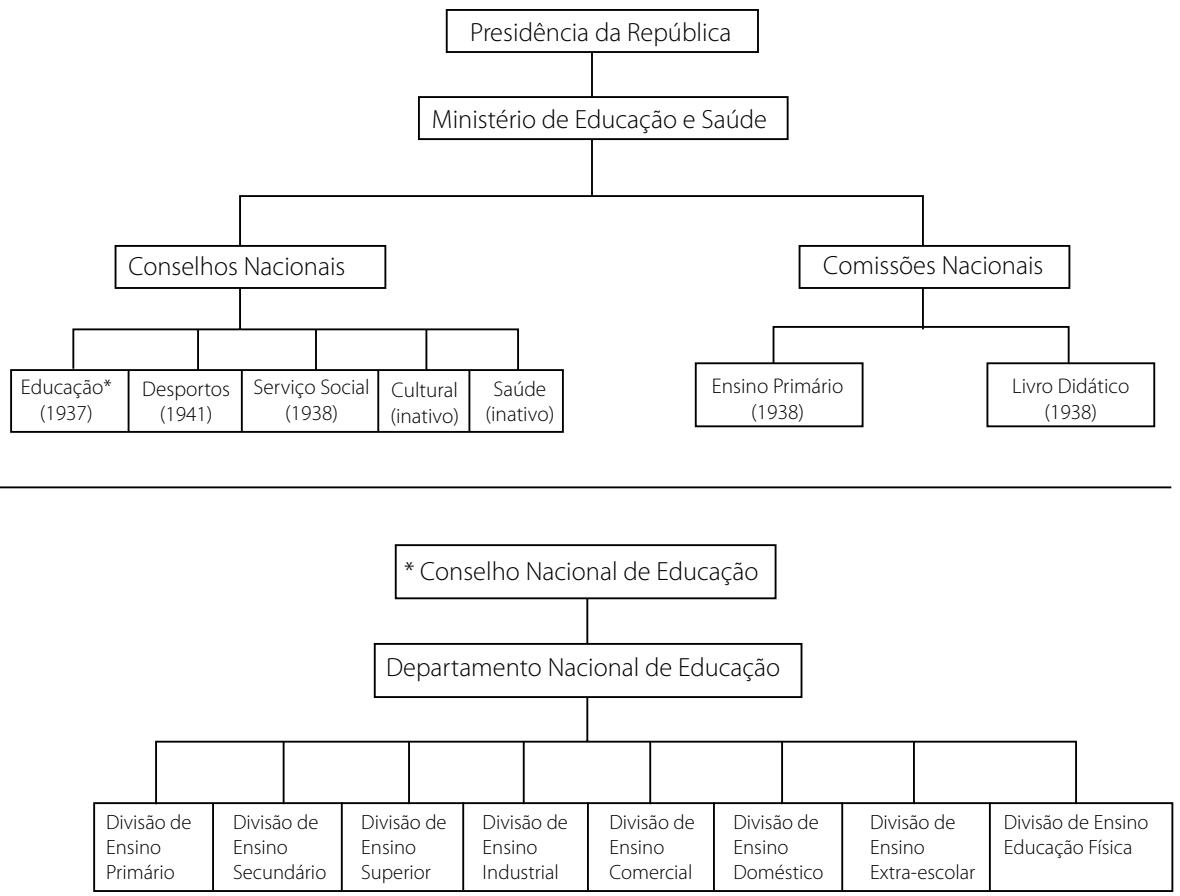

Fonte: Ferreira, 2008, p.34.

dava diretamente, não na produção, como já mencionamos, mas pela censura segundo as diretrizes indicadas para a produção dos livros didáticos, e ainda mais, com base na orientação para reformulação dos manuais avaliados. Segundo Juliana Miranda Filgueiras,

De acordo com o decreto-lei n. 1.006/38, a CNLD poderia indicar modificações a serem feitas nos textos dos livros examinados, para que fosse possível sua autorização. A obra depois de modificada deveria ser novamente submetida a exame da CNLD, para decisão final. Os livros didáticos autorizados receberiam um número de registro, que deveria aparecer na capa, juntamente com a frase: "livro de uso autorizado pelo Ministério da Educação". A reedição de livros didáticos autorizados, que não possuíssem grandes alterações, não precisava passar por nova avaliação, mas a reedição deveria ser comunicada à CNLD. Em janeiro de cada ano o Ministério da Educação divulgaria no Diário Oficial a relação dos manuais de uso autorizado. (Filgueiras, 2008, p.2) 
A Comissão, como analisou a autora, tinha o poder de indicar alterações dos conteúdos dos livros avaliados e indicar sua liberação para publicação e veiculação condicionada a nova apresentação aos avaliadores. Somente livros que tivessem poucas alterações sugeridas poderiam receber o número de registro e a frase "livro de uso autorizado pelo Ministério da Educação" sem passar por nova avaliação da Comissão. O processo e as diretrizes utilizadas pela Comissão para avaliação dos manuais submetidos para análise, conforme mostrou Filgueiras, eram divididos em duas partes. Na primeira vemos:

Art. 20. Não poderá ser autorizado o uso do livro didático:

a) que atente, de qualquer forma, contra a unidade, a independência ou a honra nacional;

b) que contenha, de modo explícito, ou implícito, pregação ideológica ou indicação da violência contra o regime político adotado pela Nação;

c) que envolva qualquer ofensa ao Chefe da Nação, ou às autoridades constituídas, ao Exército, à Marinha, ou às demais instituições nacionais;

d) que despreze ou escureça as tradições nacionais, ou tente deslustrar as figuras dos que se bateram ou se sacrificaram pela pátria;

e) que encerre qualquer afirmação ou sugestão que induza o pessimismo quanto ao poder e ao destino da raça brasileira;

f) que inspire o sentimento da superioridade ou inferioridade do homem de uma região do país, com relação ao das demais regiões;

g) que incite ódio contra as raças e as nações estrangeiras;

h) que desperte ou alimente a oposição e a luta entre as classes sociais;

i) que procure negar ou destruir o sentimento religioso, ou envolva combate a qualquer confissão religiosa;

j) que atente contra a família, ou pregue ou insinue contra a indissolubilidade dos vínculos conjugais;

k) que inspire o desamor à virtude, induza o sentimento da inutilidade ou desnecessidade do esforço individual, ou combata as legítimas prerrogativas da personalidade humana. (Decreto-Lei n. 1.006/38, p.4)

Nessa primeira parte, mais centrada nas questões de conteúdo, vemos claramente a preocupação com um ensino centrado na educação cívica, para a formação de uma mentalidade patriótica. E ainda mais, na letra 'c' 
encontramos o cerceamento de qualquer tipo de crítica ao regime instituído, pois como registrado, seria vetado o livro que ofendesse o 'Chefe', nesse caso Getúlio Vargas, ou mesmo as instituições nacionais. Toda e qualquer análise do governo vigente ficava assim vetada. Na segunda parte, centrada na apresentação e metodologia do livro, vemos:

Art. 21. Ser ainda negada autorização de uso ao livro didático:

a) que esteja escrito em linguagem defeituosa, quer pela incorreção gramatical, quer pelo inconveniente ou abusivo emprego de termos ou expressões regionais ou da gíria, quer pela obscuridade do estilo;

b) que apresente $\mathrm{o}$ assunto com erros da natureza científica ou técnica;

c) que esteja redigido de maneira inadequada, pela violação dos preceitos fundamentais da pedagogia ou pela inobservância das normas didáticas oficialmente adotadas, ou que esteja impresso em desacordo com os preceitos essenciais da higiene da visão;

d) que não traga por extenso o nome do autor ou autores;

e) que não contenha a declaração do preço de venda, o qual não poderá ser excessivo em face do seu custo.

Art. 22. Não se concederá autorização, para uso no ensino primário, de livros didáticos que não estejam escritos na língua nacional.

Art. 23. Não será autorizado uso do livro didático que, escrito em língua nacional, não adote a ortografia estabelecida pela lei. (Decreto-Lei n. 1.006/38, p.4-5)

Conforme apresentado no Decreto-Lei 1.006/38, desde a forma de apresentação dos livros didáticos até a ortografia, a língua e mesmo a proibição de termos regionais eram reguladas pela Comissão. Portanto, toda e qualquer editora, assim como autores que fossem submeter seus livros para avaliação, teriam de seguir as indicações do Decreto. Tal análise corrobora a afirmação de Luca, segundo a qual "o regime não apenas interferiu de forma incisiva no campo educacional, mas levou a cabo, desde a subida de Vargas ao poder, um processo de centralização e expansão da máquina burocrática que, aliado a um ambicioso projeto no âmbito da cultura, alterou as relações entre intelectualidade e Estado" (Luca, 2009, p.168). Nessa citação a autora nos propõe refletir sobre a aproximação gradual que foi estabelecida entre os autores, seus editores e o Estado. Ainda mais do que isso, nos possibilita percebermos que a avaliação 
e regulação dos livros didáticos durante o Estado Novo foram fundamentais instrumentos de legitimação do sistema político instituído pelo novo regime.

Essa aproximação foi estimulada pelo Ministério da Educação mediante ações como empréstimos bancários às editoras, além do fornecimento de papel ou até mesmo a inclusão de seus títulos nas listas recomendadas pela CNLD. Nesse contexto, o Departamento de Imprensa e Propaganda (DIP), de acordo com Luca, teve o papel de promulgar "atividades editoriais que pretendiam difundir o projeto cultural e as realizações do regime e do chefe do Estado" (Luca, 2009, p.169), além de censurar os manuais que apresentassem ideias contraditórias às diretrizes da CNLD. Nesse ínterim, não podemos desconsiderar que as políticas educacionais implementadas pelo governo Vargas, sob os Ministérios de Francisco Campos e Gustavo Capanema, estimularam a ampliação da produção de livros didáticos, não apenas pela impossibilidade de importação, devido ao contexto conturbado do entre-guerras, mas também pelas mudanças implementadas na estrutura do ensino brasileiro. De acordo com Luca,

houve nesse período uma vigorosa expansão do mercado editorial, favorecida tanto pelo aumento do letramento, por reformas no ensino secundário e pela ampliação do segmento superior, além da própria conjuntura econômica interna e externa, pouco propícia à importação de livros. Esse conjunto completo de fatores alterou as condições de exercício da atividade intelectual e chegou mesmo a permitir a existência do "romancista em tempo integral". (Luca, 2009, p.168)

Os livros didáticos deixaram paulatinamente de ser produção secundária ou hobby de seus autores, mas o próprio objeto de seu investimento, como afirmou a autora. Entretanto, essa profissionalização da produção dos manuais escolares os empurrava cada vez mais ao seu lugar de produto comercial e, portanto, subjugado às regras de mercado. Ainda de acordo com Luca, até mesmo grandes editores como José Olympio, que não tinham entre suas publicações os livros didáticos enquanto produtos centrais, investiram em alguns títulos, "como atesta a edição do volume História do Brasil (1944), de Otávio Tarquínio de Souza e Sérgio Buarque de Holanda, destinado à $3^{a}$ série do curso secundário e que, segundo informa na capa, estava, "de acordo com o programa oficial" (Luca, 2009, p.169). Em exemplos como esse, vemos a orientação seguida pelas editoras que se propunham a publicar manuais escolares. 
Dessa forma, a partir da criação da CNLD institui-se no Brasil uma nova cultura editorial que investirá em manuais escolares a partir de orientações dos governos, visando sua aprovação, ou até, como ocorre nos dias atuais, a aquisição dos livros/produtos pelo próprio Estado. Mas esta última observação será foco da análise que nos propomos realizar a seguir.

\section{O Plano Nacional do Livro Didático: (Des)Continuidades}

Ao discorrermos sobre a CNLD existente durante o Estado Novo percebemos o quanto ela, apesar de falha em muitos aspectos, correspondeu aos objetivos da política educacional daquele governo, enquanto instrumento de construção de uma nova nacionalidade. Notamos também que a partir da atuação dessa Comissão surgiu uma nova relação entre o Estado, as editoras e os autores de livros didáticos e, com isso, iniciou-se a normatização dos manuais escolares, que passaram a ser adequados às diretrizes de avaliação do Ministério de Educação e Saúde. Essas diretrizes estiveram em vigor até 1961, como demonstramos; depois, outras políticas as substituíram até chegarmos à criação do Programa Nacional do Livro Didático (PNLD). Entre o fim da CNLD e a implementação do PNLD, tivemos um período demarcado pelas políticas educacionais do governo militar, que por serem também delineadas por perspectivas ideológicas autoritárias já foram foco de muitos estudos. De acordo com Miranda e Luca, "neste contexto particular, destaca-se o peso da interferência de pressões e interesses econômicos sobre a história ensinada, na medida em que os governos militares estimularam, por meio de incentivos fiscais, investimentos no setor editorial e no parque gráfico nacional que exerceram papel importante no processo de massificação do uso do livro didático no Brasil” (Miranda; Luca, 2004, p.125). Conforme afirmaram as autoras, a implementação de políticas de regulação dos livros didáticos durante o governo militar contribuiu para manter a cultura de vinculação entre a produção editorial dos manuais escolares e as diretrizes governamentais para esses. Apesar de essas políticas não serem nosso foco de análise, não podemos deixar de mencioná-las, pois foram de alguma forma o elo condutor entre a visão da CNLD e a criação do PNLD. De acordo com Miranda e Luca, 
sob o período militar, a questão da compra e distribuição de livros didáticos recebeu tratamento específico do poder público em contextos diferenciados - 1966, 1971 e 1976 -, todos marcados, porém, pela censura e ausência de liberdades democráticas. De outra parte, esse momento foi marcado pela progressiva ampliação da população escolar, em um movimento de massificação do ensino cujas consequências, sob o ponto de vista da qualidade, acabariam por deixar marcas indeléveis no sistema público de ensino e que persistem como o seu maior desafio. (Miranda; Luca, 2004, p.125)

Os manuais escolares nesse período tinham a função de levar às escolas a ideologia do governo militar, o que não foi diferente do estabelecido no período do Estado Novo. De acordo com Monteiro, as políticas educacionais centradas na regulação dos livros didáticos, durante o período militar foram caracterizadas por esforços no "sentido de exercer maior controle e censura, ao mesmo tempo que incentivos fiscais e investimentos no parque gráfico nacional induziam o processo de massificação do uso do livro didático no Brasil, a fim de atender à demanda da população escolar, que aumentou significativamente nesse período" (Monteiro, 2009, p.180-181). Com preocupações relativas ao controle ideológico, o governo militar não apenas censurava as publicações dos livros didáticos, como de forma semelhante ao efetivado durante o Estado Novo, investia financeiramente no parque industrial brasileiro com vistas a aproximar as relações entre editores e Estado, como demonstrou a autora. Essa aproximação criava uma relação de dependência que levava de forma silenciosa à autocensura das produções e publicações dos livros didáticos no Brasil. Na mesma direção de análise podemos observar que não apenas as produções dos livros didáticos eram alvo dos sistemas de controle do governo militar, como também e já mencionado, o ensino de história dentro de suas potencialidades críticas também sofreu restrições, assim como a produção de livros didáticos na área. De acordo com Monteiro,

Do ponto de vista da promoção de valores e do controle da produção editorial, o ensino de história e geografia, por exemplo, sofre fortes pressões político-ideológicas. A substituição dessas disciplinas no currículo do então $1^{\circ}$ grau pela disciplina escolar "estudos sociais", e a inclusão das disciplinas "educação moral e cívica" e "organização política e social do Brasil” (OSPB), acabou por representar não 
só sua eliminação do currículo, mas também uma tentativa de eliminar a dimensão crítica do ensino. (Monteiro, 2009, p.181)

A substituição das disciplinas de história e geografia por outras, como as citadas pela autora, estimulou as mudanças na produção dos livros didáticos, tanto de história, como de geografia, pois esses agora deveriam atender as novas demandas. Entretanto, o que queremos discutir aqui se centra neste questionamento: apesar dos contextos diferentes, quais a aproximações e os distanciamentos entre a atuação da CNLD e o PNLD? Facilmente podemos responder que o primeiro foi um instrumento de veiculação ideológica do Estado Novo, enquanto o segundo é um instrumento de avaliação voltado a garantir a qualidade do ensino nos governos pós-ditadura militar, ou seja, democráticos, no Brasil. Essa diferença contextual apresentada pode enganar o olhar do analista que considere o objetivo da criação e manutenção dos dois órgãos, no entanto, nossa análise se centra no papel desenvolvido por eles. Apesar de objetivos diferentes, é preciso percebermos que ao ditar diretrizes de avaliação, tanto a CNLD quanto o PNLD contribuíram e contribuem para a uniformização das formas de apresentação dos conteúdos nos livros didáticos.

O PNLD foi criado, como já referido, em 1985, entretanto, somente passou à função de aquisição e distribuição ampla dos livros didáticos para as escolas públicas a partir de 1995. Sua criação se insere dentro das discussões iniciadas a partir da abertura política no final do governo militar.

A partir da década de 1980, na conjuntura da reconstrução democrática, algumas tímidas ações no âmbito da Fundação de Assistência ao Estudante tangenciaram a discussão acerca dos problemas presentes nos livros didáticos distribuídos no território nacional. Esse movimento coincidiu com importantes debates a respeito dos programas oficiais de História, levados a efeito, sobretudo - mas não exclusivamente - nos estados de Minas Gerais e São Paulo. Marco na política em relação aos materiais didáticos foi a criação, em 1985, do Programa Nacional do Livro Didático - PNLD. (Miranda; Luca, 2004, p.125)

A preocupação dos educadores nesse momento era possibilitar novas produções de livros didáticos livres da ideologia autoritária do governo militar. Tais debates, na década de 1980, contribuíram para a reformulação do ensino 
de História. Esse interesse dos educadores em mudanças nas publicações nas áreas de História iam ao encontro das diretrizes traçadas pelo já influente Banco Mundial, o qual, segundo Monteiro, desde a década de 1990, desaconselhava o Brasil a realizar profundas alterações no currículo escolar para melhorar o ensino no país, pelo contrário, indicava a necessidade de aumentar a qualidade dos livros didáticos, pois consideravam que "neles é que se condensam os conteúdos e se orientam as atividades que guiam tanto os alunos quanto os professores" (Monteiro, 2009, p.179). Essa perspectiva que entendia o livro didático como o responsável pelas melhorias ou fracassos do ensino influiu diretamente nas propostas educacionais posteriores, assim como na criação do PNLD. O livro didático, como analisado no início deste trabalho, deixou de ser entendido como recurso didático, e,

De instrumentos auxiliares do processo de ensino/aprendizagem, os livros didáticos passaram a ser cada vez mais reconhecidos e indicados, nas políticas educacionais, como documentos de importância estratégica para viabilizar as mudanças e melhorias que se fazem necessárias na educação básica dos países em desenvolvimento, inclusive demonstrando maior efetividade do que a produção de propostas curriculares inovadoras. (Monteiro, 2009, p.179)

O livro, nessa visão, seria o responsável por guiar o professor para a realização de boas formas de ensino. E assim, ainda de acordo com a autora, "nessa perspectiva, um bom livro didático nas mãos dos professores, além de evitar erros no ensino, possibilitaria a introdução de metodologias inovadoras, a atualização de conteúdos e a implementação de processos de ensino/aprendizagem criativos e afinados com o que há de mais novo em termos de pesquisa educacional" (Monteiro, 2009, p.179). O ensino seria estritamente dependente da qualidade dos livros didáticos, como apontou a autora, e não especificamente sua qualidade estaria atrelada à qualidade da formação dos professores ou mesmo da estrutura e dos recursos ofertados pelas escolas ao provimento dos recursos didáticos. O professor seria apenas uma peça menor no processo de ensino/aprendizagem e não sujeito integrante do processo; sem um livro de boa qualidade nas mãos, seria totalmente incapaz de realizar um ensino de qualidade. Tal perspectiva, apesar de ser a grande influência nas políticas educacionais desde a criação da CNLD, é totalmente equivocada; como já discutimos, o livro pode ser um recurso valioso nas mão dos professores, mas não 
é essencial ou fundamental. Sem ele, o ensino/aprendizagem ocorre, pois se realiza na esfera de relação entre docentes e discentes.

É nesse contexto que em 1985 foi criado o PNLD. Segundo Vitória Regina Silva,

Desde a sua instituição, em 1995, e ampliação, em 1997, o Programa Nacional do Livro Didático (PNLD) vem se constituindo em uma das mais importantes políticas públicas educacionais do Brasil. Inicialmente voltado apenas para atendimento dos alunos do então $1^{\circ}$ grau (posteriormente chamado de Ensino Fundamental), foi ampliado em 2002, passando a atender também os alunos do Ensino Médio. A aprovação em novembro de 2009 da Resolução n. 60 fez com que o programa passasse a ser política de Estado, institucionalizando-se definitivamente. (Silva, 2011, p.1)

A importância do Programa apontada pela autora é pautada pela sua amplitude de atuação, pois desde sua criação está em processo de ampliação, a ponto de se tornar uma política de Estado e atender todo o processo formativo dos alunos brasileiros desde as séries iniciais até o ensino Médio, por meio da avaliação e distribuição dos livros didáticos que são utilizados nesses níveis de ensino. Mas, somente a partir de 1996, em outro contexto, não mais demarcado pelo Estado autoritário, como analisaram Miranda e Luca (2004), o PNLD iniciou de fato a avaliação dos manuais escolares. Para as autoras,

Desde então, estipulou-se que a aquisição de obras didáticas com verbas públicas para distribuição em território nacional estaria sujeita à inscrição e avaliação prévias, segundo regras estipuladas em edital próprio. De um PNLD a outro, os referidos critérios foram aprimorados por intermédio da incorporação sistemática de múltiplos olhares, leituras e críticas interpostas ao programa e aos parâmetros de avaliação. (Miranda; Luca, 2004, p.127)

O aprimoramento dos critérios do programa, apontado pelas autoras, se deu não apenas pela percepção de suas falhas, mas também pela renovação das políticas educacionais que desde a redemocratização brasileira vêm mudando de acordo com o Ministério e a visão de governo. Não somente os critérios de avaliação se alteraram, também os de inscrição das obras. Em 1999, por exemplo, o PNLD aceitou a inscrição de obras isoladas por editora e não apenas coleções, como anteriormente. Contudo, a partir de 2002, como analisaram 
Miranda e Luca, incorporaram-se na área de História análises estatísticas para avaliar o desempenho de cada coleção em relação aos quesitos da ficha de avaliação dos avaliadores e que é divulgada no Guia do programa, conforme podemos visualizar na Figura 2:

Figura 2

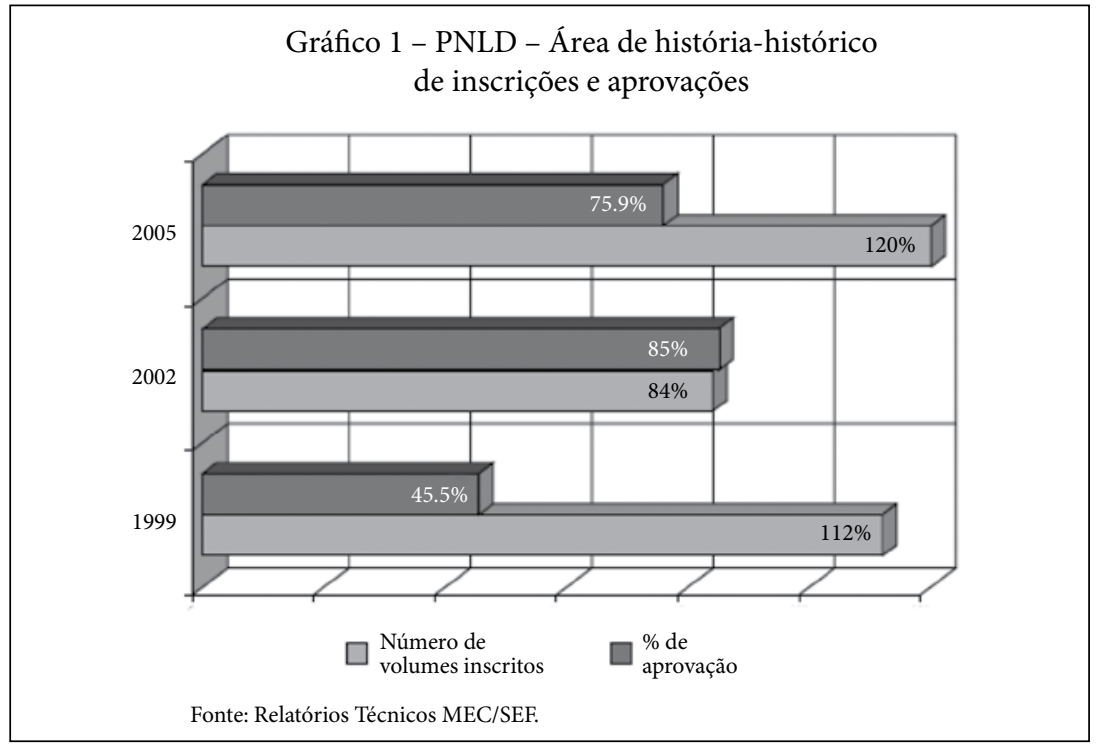

Fonte: Miranda; Luca, 2004, p.127.

No gráfico vemos que entre 1999 e 2005 a porcentagem na área de História de coleções aprovadas em relação às inscrições foi gradativamente aumentando. Podemos inferir a partir desses dados que, aos poucos, os editores e escritores foram se adaptando aos critérios do programa até chegar à aprovação maior dos livros inscritos. Essa inferência corrobora nossa hipótese neste trabalho, a qual viemos discutindo, de que as políticas de avaliação dos livros didáticos contribuíram para a uniformização das produções e, portanto, para o cerceamento e delimitação da apresentação dos conteúdos dispostos nos manuais escolares.

É preciso considerar que o processo de avaliação dos manuais escolares realizado pelo PNLD se efetiva mediante editais lançados trienalmente. De acordo com Silva, 
Os editais são sempre identificados por um ano: PNLD 2011 ou PNLD 2012, por exemplo. $\mathrm{O}$ ano ao qual o edital se refere não é o da sua publicação, mas aquele em que os livros serão usados pela primeira vez, sendo nos dois anos seguintes adquiridos acervos complementares, de reposição (exceto no caso dos livros consumíveis, que são repostos integralmente todos os anos). (Silva, 2011, p.2)

Os editais do PNLD possuem duas fases principais: a primeira é marcada pela candidatura dos livros para avaliação e posterior liberação da listagem dos indicados; a segunda é a fase na qual os professores, a partir dessa listagem, escolhem quais livros utilizarão em suas salas de aula. A estrutura do Programa é complexa e, portanto, pouco ágil, mas tem se mostrado eficaz. Segundo Silva, todo o processo entre a aquisição dos livros e sua chegada às escolas leva ao todo cerca de 20 meses, por isso os editais, apesar de apresentarem a data de utilização dos livros, como explicado na citação anterior, são abertos muito antes. Como demonstrou a autora,

os livros que começaram a ser usados no início do ano de 2011 tiveram o seu edital publicado no final de 2008. Os livros foram inscritos no início de 2009, o resultado da avaliação publicado em meados de 2010, quando então foram escolhidos pelos professores. Durante o segundo semestre daquele ano foram feitas as negociações para a venda, a impressão e a distribuição das coleções. Se considerarmos, ainda, que a produção editorial de uma coleção não leva menos do que dois anos, os livros inscritos em 2009 começaram a ser produzidos em 2007, de onde se conclui que entre a escrita dos originais e o uso do livro na sala de aula há pelos menos um período de quatro anos. Trata-se, portanto, de uma empreitada de longo prazo, envolvendo investimentos elevados e um grande número de agentes, entre autores, equipes editoriais, funcionários do MEC e do FNDE, comissão de avaliadores (comissões técnicas e do IPT), além de toda a logística para fazer com que os livros cheguem aos mais distantes pontos do país. (Silva, 2011, p.2)

Todo o processo, como vemos, é demorado, o que leva em algumas disciplinas à defasagem dos conteúdos quando os livros chegam às salas de aula. Entretanto, esse não chega a ser um dos maiores problemas do sistema. O que percebemos aqui é o movimento que se estabelece entre as produções, ou seja, escrita dos livros didáticos, as editores que os inscrevem e as diretrizes do PNLD. Afinal, dentro de um sistema longo, podemos inferir que os manuais 
são produzidos cuidadosamente para serem aprovados pelo programa. Caso contrário, investimentos financeiros grandes seriam desperdiçados de ambos os lados, tanto das editoras quanto do governo. Esse caráter do processo de avaliação dos manuais didáticos demonstra como o PNLD influi de forma profunda e direta no mercado editorial de livros didáticos no Brasil, pois, como afirmou Silva,

A institucionalização do PNLD e a ampliação da sua cobertura acarretaram uma profunda mudança no mercado editorial brasileiro. Ainda que compras governamentais de livros didáticos tenham ocorrido em outros tempos, a partir de 1995 elas passaram a ter uma regularidade e uma cobertura inédita. Para as editoras, a entrada do governo como grande comprador de livros representou uma significativa mudança em seu negócio, pois a venda para as escolas por meio de livrarias deixou de ser a principal fonte de faturamento. Ainda que a rentabilidade das vendas governamentais seja muito menor do que a da venda ao chamado mercado privado (o que eventualmente também inclui livros para alunos de escolas públicas), a quantidade de exemplares vendidos é incomparavelmente maior, representando parcela expressiva do giro de capital das empresas. (Silva, 2011, p.3)

O mercado editorial de livros didáticos em outros momentos da história brasileira, como no período da CNLD, era voltado não apenas para atender as diretrizes do governo, mas também o público consumidor. Isso porque os livros eram adquiridos pelos próprios alunos e suas famílias. Hoje esse cenário é fundamentalmente diferente porque o governo é o consumidor dos livros que chegarão às salas de aulas das escolas públicas. Dessa forma, como demonstrou a autora, apesar de o lucro sobre os livros de forma individual ser menor na venda para o Estado do que para livrarias, a aquisição pelo Estado tornou-se regular, e isso representa uma renda estável para as editoras. Esse contexto levou as editoras a investirem na produção regular de livros didáticos para atender a esse mercado que se abria com a aquisição estatal de manuais escolares. Outra questão central levantada por Silva é "que a aprovação ou reprovação de uma coleção no PNLD traz consequências para o desempenho da mesma no chamado mercado particular. Muitas escolas substituem os livros que adota se eles não constam da lista de obras aprovadas pelo MEC" (Silva, 2011, p.3). A avaliação do PNLD tornou-se importante para o mercado de livros didáticos não só no processo de aquisição do Estado, mas também, como 
afirmou a autora, como uma espécie de capital simbólico, como chamaria Bourdieu, pois os livros bem avaliados acabam apresentando um bom desempenho nas vendas do mercado particular. Portanto, ainda para a autora, "é inquestionável o impacto das compras governamentais na indústria do livro didático desde 1995, com uma evidente subordinação da produção das coleções aos critérios fixados pelos editais" (Silva, 2011, p.3). Novamente, vemos como o PNLD, na mesma direção do CNLD, tem contribuído para a uniformização das produções dos livros didáticos.

No entanto, quais são os critérios estabelecidos pelo PNLD? O edital do PNLD 2012, destinado à compra de livros para o Ensino Médio, apresenta os seguintes critérios de avaliação:

\subsection{Critérios eliminatórios comuns a todas as áreas}

Os critérios eliminatórios comuns a serem observados nas obras inscritas no PNLD 2012, submetidas à avaliação, são os seguintes:

(1) respeito à legislação, às diretrizes e às normas oficiais relativas ao ensino médio;

(2) observância de princípios éticos necessários à construção da cidadania e ao convívio social republicano;

(3) coerência e adequação da abordagem teórico-metodológica assumida pela obra, no que diz respeito à proposta didático-pedagógica explicitada e aos objetivos visados;

(4) correção e atualização de conceitos, informações e procedimentos;

(5) observância das características e finalidades específicas do manual do professor e adequação da obra à linha pedagógica nela apresentada;

(6) adequação da estrutura editorial e do projeto gráfico aos objetivos didáticopedagógicos da obra.

A não-observância de qualquer um desses critérios, detalhados a seguir, resultará em proposta incompatível com os objetivos estabelecidos para o ensino médio, o que justificará, ipso facto, sua exclusão do PNLD 2012.15.

Dentre os critérios eliminatórios comuns a todas as áreas avaliadas, vemos no primeiro e segundo números dois pontos comuns ao exigido pela antiga CNLD, o respeito à legislação e "às normas oficiais". Claro que não podemos considerar de igual forma, pois contextos e objetivos diferentes já foram 
discutidos, entretanto, essa regulação contribui para a uniformização dos manuais que serão produzidos dentro da visão pedagógica estabelecida pelos órgãos oficiais e não dentro da visão do autor ou de novas discussões sobre educação. Também podemos analisar que no segundo ponto a construção da cidadania é um dos fundamentos que os livros devem observar. Nos seis critérios vemos instrumentos reguladores e ao mesmo tempo normatizadores e cerceadores da produção dos livros. O edital ainda segue:

2.1.1. Respeito à legislação, às diretrizes e às normas oficiais relativas ao ensino médio

Considerando-se a legislação, as diretrizes e as normas oficiais que regulamentam o ensino médio, serão excluídas as obras didáticas que não obedecerem aos seguintes estatutos:

(1) Constituição da República Federativa do Brasil.

(2) Lei de Diretrizes e Bases da Educação Nacional, com as respectivas alterações introduzidas pelas Leis $n^{\circ} 10.639 / 2003, n^{\circ} 11.274 / 2006, n^{\circ} 11.525 / 2007$ e $n^{\circ}$ $11.645 / 2008$.

(3) Estatuto da Criança e do Adolescente.

(4) Diretrizes Curriculares Nacionais para o Ensino Médio.

(5) Resoluções e Pareceres do Conselho Nacional de Educação, em especial, o Parecer CEB no 15, de 04/07/2000, o Parecer CNE/CP no 003, de 10/03/2004 e a Resolução CNE/CP nº 01 de 17/06/2004.

2.1.2. Observância de princípios éticos e democráticos necessários à construção da cidadania e ao convívio social.

Serão excluídas do PNLD 2012, as obras didáticas que:

(1) veicularem estereótipos e preconceitos de condição social, regional, étnico-racial, de gênero, de orientação sexual, de idade ou de linguagem, assim como qualquer outra forma de discriminação ou de violação de direitos;

(2) fizerem doutrinação religiosa e/ou política, desrespeitando o caráter laico e autônomo do ensino público;

(3) utilizarem o material escolar como veículo de publicidade ou de difusão de marcas, produtos ou serviços comerciais. 
2.1.3. Coerência e adequação da abordagem teórico-metodológica assumida pela obra, no que diz respeito à proposta didático-pedagógica explicitada e aos objetivos visados.

Por mais diversificadas que sejam as concepções e as práticas de ensino envolvidas na educação escolar, propiciar ao aluno uma efetiva apropriação do conhecimento implica:

a) escolher uma abordagem metodológica capaz de contribuir para a consecução dos objetivos educacionais em jogo;

b) ser coerente com essa escolha, do ponto de vista dos objetos e recursos propostos.

Em consequência, serão excluídas as obras didáticas que não atenderem aos seguintes requisitos:

(1) explicitar, no manual do professor, os pressupostos teórico-metodológicos que fundamentam sua proposta didático-pedagógica;

(2) apresentar coerência entre essa fundamentação e o conjunto de textos, atividades, exercícios, etc. que configuram o livro do aluno; no caso de recorrer a mais de um modelo teórico-metodológico de ensino, deverá indicar claramente a articulação entre eles;

(3) organizar-se - tanto do ponto de vista dos volumes que compõem a coleção, quanto das unidades estruturadoras de cada um desses volumes ou do volume único - de forma a garantir a progressão do processo de ensino-aprendizagem;

(4) favorecer o desenvolvimento de capacidades básicas do pensamento autônomo e crítico, no que diz respeito aos objetos de ensino-aprendizagem propostos;

(5) contribuir para a apreensão das relações que se estabelecem entre os objetos de ensino-aprendizagem propostos e suas funções socioculturais...

A partir dos critérios apresentados, como já afirmamos, não apenas as formas de apresentação dos conteúdos, como também os próprios conteúdos são delineados dentro de um grupo de diretrizes estabelecidas como meio de regulação, mas que dialeticamente, cerceiam o universo de discussões pedagógicas possíveis no processo de produção dos manuais didáticos. Como já analisamos, mesmo sem produzir diretamente os livros didáticos, através do PNLD o governo participa ativamente de todo o processo de elaboração e publicação dos manuais escolares. Essa atuação do governo na própria composição dos 
livros nos chama atenção não apenas por seu caráter cerceador do universo editorial dos manuais, especificamente os de história, mas também porque precisamos levar em conta que, conforme bem analisaram as autoras Miranda e Luca, “a educação constituiu-se em veículo privilegiado para introdução de novos valores e modelagem de condutas...” (Miranda; Luca, 2004, p.125), durante o regime militar - como evidenciam na continuidade dessa citação -, mas também, em todo o processo de interferência do Estado sobre a disposição, apresentação e uniformização dos conteúdos escolares.

Dessa forma, podemos perceber que apesar de uma política que visa assegurar a qualidade do ensino nas escolas públicas, o PNLD acabou por contribuir para um processo de acomodação no qual o livro deixou de ser apenas um recurso didático, para se tornar O RECURSO DIDÁTICO, ou seja, excetuando o Ensino de Jovens e Adultos, em praticamente todos os níveis de ensino não se cogita mais a menor possibilidade da exclusão do livro didático das salas de aula. Não estamos aqui dizendo que isso é ruim ou bom, mas que é uma realidade que deve ser analisada, pois os docentes precisam ter consciência dos processos de produção dos manuais que utilizam como suportes didáticos em suas aulas. Pensar o livro didático e sua produção é ampliar as margens de reflexão sobre métodos e formas nas quais o ensino, em nosso caso de história, vem sendo efetivado no Brasil e assim, quem sabe, construir espaço para um ensino independente, consciente e crítico.

\section{FONTES}

BRASIL. Guia de livros didáticos: PNLD 2012: História, 2011.

\section{REFERENCIAS}

BAIRRO, C. C. de. Livro didático: um olhar nas entrelinhas da sua história. Disponível em: www.histedbr.fae.unicamp.br/acer_histedbr/.../Cj5GgE6L.doc.

BITTENCOURT, C. Ensino de História: fundamentos e métodos. 4.ed. São Paulo: Cortez, 2011.

Livros didáticos entre textos e imagens. In: O saber histórico na sala de aula. 11.ed. São Paulo: Contexto, 2010.

BRASIL. Lei Orgânica de Ensino 1942. Disponível em: www.histedbr.fae.unicamp.br/ 
navegando/fontes_escritas/5_Gov_Vargas/decreto-lei\%204.244-1942\%20reforma\%20capanema-ensino\%20secund\%E1rio.htm; Acesso em: 14 abr. 2012.

CERTEAU, M. de. Fazer história. In: A escrita da história. 2.ed. Rio de Janeiro: Forense Universitária, 2000.

CHOPPIN, A. História dos livros e das edições didáticas: sobre o estado da arte. $E d u$ cação e Pesquisa, São Paulo, v.30, n.3, p.549-566, set.-dez. 2004. Disponível em: www.scielo.com.br/scielo.php?pid=S1517-97022004000300012\&script=sci_arttext.

FERREIRA, R. de C. C. A Comissão Nacional do Livro Didático durante o Estado Novo (1937-1945). Dissertação (Mestrado) - Unesp. Assis (SP), 2008. Disponível em: www.athena.biblioteca.unesp.br/exlibris/bd/bas/33004048018P5/2008/ferreira rcc_me_assis.pdf; Acesso em: 14 abr. 2012.

FERRO, M. A manipulação da História no ensino e nos meios de comunicação. São Paulo: Ibrasa, 1983.

FILGUEIRAS, J. M. Os processos de avaliação de livros didáticos na Comissão Nacional do Livro Didático. In: ENCONTRO REGIONAL DE HISTÓRIA, 19. Poder, Violência e Exclusão. Anpuh/SP-USP. 8-12 set. 2008. Anais... CD-ROM. Disponível em: www.anpuhsp.org.br/sp/downloads/CD\%20XIX/PDF/Autores\%20e\%20 Artigos/Juliana\%20Miranda\%20Filgueiras.pdf; Acesso em: 14 abr. 2012.

FONSECA, S. G. Didática e prática de ensino de História. 11.ed. Campinas (SP): Papirus, 2003.

LUCA, T. R. de. Livro didático e Estado: explorando possibilidades interpretativas. In: ROCHA, H. A. B.; REZNIK, L.; MAGALHÃES, M. de S. A história na escola: autores, livros e leituras. Rio de Janeiro: Ed. FGV, 2009. p.151-172.

MAGALHÃES, J. O manual escolar no quadro da história cultural: para a historiografia do manual escolar em Portugal. Disponível em: http://hum.unne.edu.ar/investigacion/educa/alfa/UniversidaddeLisboa.pdf.

MIRANDA, S. R.; LUCA, T. R. O livro didático de história hoje: um panorama a partir do PNLD. Revista Brasileira de História, São Paulo: Anpuh, v.24, n.48, p.123144, 2004. Disponível em: www.scielo.com.br/pdf/rbh/v24n48/a06v24n48.pdf; Acesso em: 15 abr. 2012.

MONTEIRO, A. M. Professores e livros didáticos: narrativas e leituras no ensino de história. In: ROCHA, H. A. B.; REZNIK, L.; MAGALHÃES, M. de S. A história na escola: autores, livros e leituras. Rio de Janeiro: Ed. FGV, 2009. p.175-199.

OLIVEIRA, J. B. A.; GUIMARÃES, S. D. P.; BOMÉNY, H. M. B. A política do Livro Didático. São Paulo: Summus; Campinas (SP): Ed. Unicamp, 1984.

PENTEADO, H. D. Metodologia do Ensino de História e Geografia. 3.ed. São Paulo: Cortez, 2010. 
SALES, Z. E. S. de; FARIA FILHO, L. M. de. A instrução Pública em Minas Gerais: Políticas educativas e o Conselho Geral da Província (1825-1835). Disponível em: www.sbhe.org.br/novo/congressos/cbhe3/Documentos/Individ/Eixo3/225.pdf; Acesso em: 11 abr. 2012.

SCHMIDT, M. A.; CAINELLI, M. Ensinar História. 2.ed. São Paulo: Scipione, 2009.

SILVA. V. R. e. Para onde vamos? O ensino de História segundo os critérios dos Editais do PNLD (2000 a 2013). In: ENCONTRO NACIONAL DOS PESQUISADORES DO ENSINO DE HISTÓRIA, 9. Florianópolis (SC), 18-20 abr. 2011. Anais Eletrônicos... Disponível em: http://abeh.org/trabalhos/GT10/tcompletovitoria. pdf; Acesso em: 15 abr. 2012.

SOUZA, R. F. de. Inovação educacional no século XIX: a construção do currículo da escola primária no Brasil. Disponível em: www.scielo.br/pdf/ccedes/v20n51/ a02v2051.pdf; Acesso em: 11 abr. 2012.

THOMPSON, J. B. Ideologia e cultura moderna: teoria social e crítica na era dos meios de comunicação de massa. 7.ed. Petrópolis (RJ): Vozes, 2007.

Artigo recebido em setembro de 2013. Aprovado em outubro de 2013. 